\title{
Efficacy and complications of open and minimally invasive surgery in acute Achilles tendon rupture: a prospective randomised clinical study_preliminary report
}

\author{
Lukas Kołodziej • Andrzej Bohatyrewicz • \\ Justyna Kromuszczyńska • Jarosław Jezierski • \\ Maciej Biedroń
}

Received: 1 November 2012 / Accepted: 20 November 2012 /Published online: 19 December 2012

(C) The Author(s) 2012. This article is published with open access at Springerlink.com

\begin{abstract}
Purpose Surgical treatment of an acute Achilles tendon rupture can effectively reduce the risk of re-rupture, but it increases the probability of surgical complications. We postulated that a minimally invasive surgical treatment might reduce the number of complications related to open surgery and improve the functional results.

Method We enrolled 47 patients with acute Achilles tendon ruptures in a prospective, randomised trial to compare clinical results and complications between a minimally invasive procedure with the Achillon ${ }^{\circledR}$ device and traditional open surgery with Krackow-type sutures. The average patient age was 46 years. The follow up time was 24 months.

Results No Achilles tendon re-rupture or nerve injury occurred in treated patients. There were two cases of wound infections in the open surgery group, and one superficial wound infection occurred in the minimally invasive group. The groups were not significantly different in the amount of pain, range of ankle movements, the single heel-rise test, calf circumference, or time to return to work and sports.
\end{abstract}

Ł. Kołodziej $(\bowtie) \cdot$ A. Bohatyrewicz

Department of Orthopaedics, Traumatology

and Musculoskeletal Oncology,

Pomeranian Medical University,

Szczecin, Poland

e-mail: lukas@hot.pl

J. Kromuszczyńska $\cdot$ J. Jezierski $\cdot$ M. Biedroń

Student's Orthopaedic Scientific Society Pomeranian

Medical University in Szczecin,

Szczecin, Poland
Conclusion After a two year follow-up period, we found no significant differences in clinical outcomes between groups treated with traditional open surgery or minimally invasive surgery.

\section{Introduction}

There is a lack of agreement of the optimal treatment for the acute Achilles tendon rupture (AATR). Reports in the literature are equivocal or even contradictory. Currently, there are four different types of interventions, including two types of surgical repair, (1) open, or (2) minimally invasive procedures; and two types of nonoperative, conservative management, (3) simple immobilisation, or (4) functional bracing. Surgical repair runs the risk of complications, such as wound dehiscence and infection, sural nerve injury, or scar and tissue adhesions. Nonsurgical management runs the risk of tendon re-rupture and poor functional outcome, and is regarded as alternative more suited to older patients. Minimally invasive procedures should reduce the risk of surgical complications, but retain other benefits of surgical treatment, particularly functional improvements with less time away from work and sports [1-3]. This study aimed to compare the efficacy of open surgery with a minimally invasive procedure performed with Achillon ${ }^{\circledR}$ device (Integra, NewDeal).

\section{Materials and methods}

Patients were included in the study when they appeared in our institution within seven days of an AATR with a 
positive clinical diagnosis on the Thompson squeeze test, exhibited a palpable gap, showed loss of plantar flexion strength, were over 18 years old and provided written agreement to participate in the study. Patients were excluded when they had chronic (neglected) tears, concomitant injuries, open tears, avulsion from the calcaneus, or systemic diseases such as rheumatoid arthritis, diabetes, or any disease such as required medications that might impair tendon healing (e.g., corticosteroids, fluorochinolones). Patients with general surgical contraindications were also excluded from the study.

After gaining approval from the institutional ethical committee, patient recruitment began in March 2008 and continued until June 2010. We invited 57 consecutive patients that fulfilled the inclusion criteria to participate in the study; six (10\%) patients refused and were treated according to the surgeon's preference; 51 patients provided written consent and were included in the study. We implemented a simple randomisation protocol, where patients were asked to choose one of two opaque envelopes that contained a paper indicating the type of surgery. Group I ( $n=24$ patients) was treated with the minimally invasive procedure with the Achillon ${ }^{\circledR}$ device and Group II ( $n=27$ patients) were treated with traditional open surgery with Krackow-type sutures. Four patients were lost to follow-up. A total of 22 patients from Group 1 and 25 patients from Group II were available at the last follow-up. The observation period was 24 months. The mean age in Group I was 44.8 years (from 30 to 62 years, SD 9.2) and in Group II, 47.1 years (from 26 to 74 years, SD 13.3). The AATR had occurred during sports activities in 35 patients $(75 \%)$, during work in seven patients $(15 \%)$, and in home accidents in five patients $(10 \%)$. Only two females participated in the study, and one was enrolled to each treatment group. All patients were treated on the first day after admission and discharged home the following day. All procedures were performed under spinal anaesthesia with a tightly applied tourniquet $(300 \mathrm{mmHg})$. As a routine, we administered one dose of prophylactic antibiotic (cefazoline). Each patient was treated with monofilament, absorbable polydioxanone (PDS, Ethicon) or polyglyconate (Maxon, Covidien) sutures. Two consultant orthopaedic surgeons, experienced in both surgical techniques, performed all treatments. The postoperative protocol was identical in both groups. Immediately after surgery, patients were placed in a below-the-knee cast that provided approximately $20^{\circ}$ plantar flexion for six weeks. All patients were asked to walk on crutches without bearing weight on the affected ankle. Low molecular-weight heparin injections were given during the cast immobilisation period to prevent deep vein thrombosis and pulmonary embolism. After six weeks, the cast was removed, and full weight bearing was allowed. No formal physiotherapy protocol was administered. Two orthopaedic residents, not involved in the treatment process, performed the last followup assessment.
Primary outcome measures were the number of important surgical complications, including infections, Achilles tendon re-ruptures, and sural nerve lesions. Secondary outcomes were pain, assessed by the Visual Analog Scale (VAS), time to return to work, ability to return to sports or pre-rupture activity levels, calf circumference, strength of calf muscles (measured by a single heel-rise test), range of ankle movements, and the length and appearance of the surgical scar. Patients were asked to assess scar cosmesis subjectively as very good, good, acceptable, or unacceptable.

\section{Statistical analysis}

The normal distribution of each parameter was tested with the Shapiro-Wilk test. The critical level of significance was $p=$ 0.05 . For parameters with normal distributions and homogeneous variances, the Student's $t$-test was used to evaluate significant differences in mean values. The homogeneity of variance was determined with Levene's test. For parameters with non-uniform variations, we applied the Cochran-Cox test. For parameters with non-normal distributions, the nonparametric Mann-Whitney test was used to evaluate significant differences in mean values. Qualitative parameters were compared using the Chi-square test. All analyses were performed with Statistica Pl software, version 10.

\section{Results}

There were no Achilles tendon re-ruptures or sural nerve lesions observed in either group. One wound infection occurred in Group I, and two occurred in Group II. One patient from Group II required readmission for surgical debridement and removal of a portion of tendon that was necrotic and infected. He reported persistent pain, with a VAS assessment of grade 7 , and he was a candidate for further surgery. The two other cases of infected, delayed wound healing resolved with oral antibiotic and local treatments. The average VAS in Groups I and II were 1.6 and 1.7, respectively $(p>0.05)$. Values of measured clinical parameters after treatment for AATR are presented in Table 1 . The only statistically important difference between groups was the scar length $(p<0.05)$. Two patients in Group II developed keloid formations, but both considered the outcome as acceptable. Out of the 35 patients that sustained the AATR during a sporting activity, only 16 (46\%; nine in group I and seven in group II) returned to their previous activity level; seven $(20 \%)$ stated that they were unable to perform their sporting activity at the previous level, and 12 (34\%) changed sports disciplines. A similar number of patients in each group returned to their original sport activity. Out of 19 patients that discontinued their sport, nine (47\%) belonged to Group I, and ten (53\%) to Group II. All patients returned to their previous work, except the one 
Table 1 Measured clinical parameters between Group I and Group II after treatment for acute Achilles tendon rupture

\begin{tabular}{lcc}
\hline & $\begin{array}{c}\text { Group I: minimally invasive } \\
\text { procedure Average value (SD) }\end{array}$ & $\begin{array}{l}\text { Group II: open surgery } \\
\text { Average value (SD) }\end{array}$ \\
\hline Ankle dorsiflexion - treated limb (degrees) & $14.2(5.1)$ & $12.6(4.2)$ \\
Ankle plantar flexion - treated limb (degrees) & $39.6(8.1)$ & $41.6(10.8)$ \\
Calf circumference - treated limb (centimeters) & $36.4(3.3)$ & $37.4(4.8)$ \\
Single heel-rise test (number of repetitions on the affected limb) & $15.2(6.3)$ & 0.40 \\
Scar length (centimeters) & $4.0(0.9)$ & 0.50 \\
Time to return to work (weeks) & $4.8(2.2)$ & 0.53 \\
\hline
\end{tabular}

that required a re-operation due to a septic complication; that patient remained on sick leave.

\section{Discussion}

The Achilles tendon is the most commonly injured tendon in recreational athletes, and the incidence is rising due to increasing numbers of people attempting to remain active and maintain fitness [1, 4]. Regardless of the treatment method, some functional deficits may persist for more than ten years after an AATR $[5,6]$. Four recently published meta-analyses of randomised control trials suggested that open surgical treatment of AATR can reduce the risk of re-ruptures compared to nonoperative treatments; however, open surgery runs significant risk of surgical complications, including surgical site infections, nerve injuries, and skin adhesions $[1-3,7]$. AATR can heal in continuity, resulting in a lengthened tendon, with decreased push off, muscle weakness, gait abnormalities and need for repeated surgery and shortening [8].

Some authors reported that percutaneous and minimally invasive techniques could limit the number of surgical complications [9-11]. Several different minimally invasive surgical techniques and special devices have been introduced to perform percutaneous or minimally invasive repairs [12-17]. Data from meta-analyses have supported minimally invasive surgery, because it decreased the risk of superficial wound infection and provided high patient satisfaction. However, no statistically significant difference was found between minimally invasive and open surgery for Achilles tendon repairs with respect to the incidence of the most disastrous complications; i.e., re-rupture and deep infection rates [2]. In a prospective study, Guillo et al. reported excellent results with a minimally invasive technique in terms of muscle strength and return to activity at pre-injury or better levels (more than $90 \%$ ), but they did not have a control group for comparison [17]. Gigante et al. compared open and percutaneous procedures, and found that both methods afforded similar restoration of clinical, ultrasound, and isokinetic patterns [18]. On the other hand, in a series of 124 cases, Maes et al. applied percutaneous repairs with the Tenolig device, and they reported a $10 \%$ re-rupture rate and a $6.5 \%$ sural nerve injury rate [19]. Taglialavoro et al. confirmed a high complication rate $(33 \%)$ with the Tenolig ${ }^{\mathrm{TM}}$ device [4].

In 2002, Assal et al. proposed a limited open procedure with a specialized jig called the Achillon ${ }^{\circledR}$ device. They reported excellent mid-term results, and no problems were reported with wound healing, infections, or sensory disturbances in sural nerves. All patients returned to their previous professional or sporting activities [16]. An in vitro biomechanical cadaveric study demonstrated that the Achillon ${ }^{\circledR}$ device offered stronger repair than the classic Krackow procedure [20]. Longo et al. also confirmed excellent biomechanical performance and stability with an Achillon-like suture configuration [21]. Garrido et al. and Feldbrin et al. reported highly satisfactory clinical results with the Achillon ${ }^{\circledR}$ device $[10,23]$. In the present study, the Achillon ${ }^{\circledR}$ suture guide provided excellent results; it facilitated tendon healing and avoided surgical complications. However, for patient and doctor, the most important outcomes, the rerupture and infection rates, were not significantly different from those observed after open surgery. One of the most important secondary outcome measures was the standing heel-rise test. This simple, readily available test can be performed in every physician's office, and it offers clinicians a reliable assessment of calf-muscle performance. The heel-rise appears to be an important early achievement in the Achilles tendon healing process; it reflects the general level of healing, and it influences patient-reported outcome and subsequent physical activity [24, 25]. In our study, the average number of heel-rise repetitions was similar in both groups, but below the 25 repetitions recommended by Lundsford for displaying normal function [25].

All but one patient in the series returned to their previous job, but only $46 \%$ regained their previous sporting activity level. Post-treatment sport activity measurements incorporated both function and physical activity as a secondary outcome [24]. In other studies that assessed minimally invasive Achilles tendon surgery, a majority of patients returned to the pre-injury activity level [10, 23]. For example, Guillo et al. and Talbot et al. reported that $80 \%$ and $74 \%$ of patients, respectively, had returned to pre-operative activity levels $[17,26]$. In our study, the radical decline observed in post-treatment sporting activities, in the authors' opinion, was due to the long period of nonweight bearing and cast immobilisation. Both treated groups 
received similar, traditional postoperative treatment regimens established at our institution. After an average of ten years follow-up, Horstmann et al. found significant functional deficits in muscle strength, endurance, and muscle activity, measured with dynamometry and electromyography in patients treated surgically, followed by six weeks of immobilisation in a cast [5]. In recent studies, early range of motion and immediate weight bearing activities were strongly recommended for both surgical and nonoperative treatments $[3,10,24,26,27]$. A randomised, control trial performed by Twaddle et al. supported early motion; in patients that received either surgical or nonsurgical treatment, they observed comparable functional results and a low recurrent rupture rate. That suggested that early motion was one of the most the important factors in recovery after AATR [28]. We believe that a radical decline in sporting activity levels reflected functional deficits created by immobilisation, non-weight bearing and lack of rehabilitation protocols. Changes in post-treatment protocol are necessary to improve the functional results. The excellent biomechanical results with the Achillon ${ }^{\circledR}$ suture system provided motivation for further study with immediate weight bearing and early, controlled movement regimens.

A limitation of our study was that we did not use a blinding method to avoid a detection bias. Another drawback was that our results represented treatments by two surgeons that treated patients similarly, but not identically; for example, there could be differences in the method of inserting the Achillon ${ }^{\circledR}$ jig, operation times, tissue handling, tissue layer closure procedures, etc. [22].

\section{Conclusions}

Minimally invasive AATR surgery performed with the Achillon ${ }^{\circledR}$ device limited the incidence of the most severe surgical complications, such as infection and tendon rerupture; however, the results were not significantly different from those using traditional open surgery.

Conflicts of Interest The authors declare that they have no conflict of interest.

Open Access This article is distributed under the terms of the Creative Commons Attribution License which permits any use, distribution, and reproduction in any medium, provided the original author(s) and the source are credited.

\section{References}

1. Khan RJ, Carey Smith RL (2010) Surgical interventions for treating acute Achilles tendon ruptures. Cochrane Database Syst Rev 9: CD003674
2. McMahon SE, Smith TO, Hing CB (2011) A meta-analysis of randomised controlled trials comparing conventional to minimally invasive approaches for repair of an Achilles tendon rupture. Foot Ankle Surg 17:211-217

3. Jiang N, Wang B, Chen A, Dong F, Yu B (2012) Operative versus nonoperative treatment for acute Achilles tendon rupture: a meta-analysis based on current evidence. Int Orthop $36: 765-773$

4. Taglialavoro G, Biz C, Mastrangelo G, Aldegheri R (2011) The repair of the Achilles tendon rupture: comparison of two percutaneous techniques. Strategies Trauma Limb Reconstr 6:147-154. doi:10.1007/s11751-011-0124-1

5. Horstmann T, Lukas C, Merk J, Brauner T, Mündermann A (2012) Deficits 10 years after Achilles tendon repair. Jnt Sports Med 33:474-479

6. Olsson N, Nilsson-Helander K, Karlsson J, Eriksson BI, Thomée R, Faxén E, Silbernagel KG (2011) Major functional deficits persist 2 years after acute Achilles tendon rupture. Knee Surg Sports Traumatol Arthrosc 19:1385-1393

7. Wilkins R, Bisson LJ (2012) Operative versus nonoperative management of acute Achilles tendon ruptures: a quantitative systematic review of randomized controlled trials. Am J Sports Med 40:2154-2160. doi:10.1177/0363546512453293

8. Maffulli N, Spiezia F, Longo UG, Denaro V (2012) Z-shortening of healed, elongated Achilles tendon rupture. Int Orthop 36:20872093. doi:10.1007/s00264-012-1602-x

9. Aktas S, Kocaoglu B (2009) Open versus minimal invasive repair with Achillon device. Foot Ankle Int 30:391-397

10. Garrido IM, Deval JC, Bosch MN, Mediavilla DH, Garcia VP, González MS (2010) Treatment of acute Achilles tendon ruptures with Achillon device: clinical outcomes and kinetic gait analysis. Foot Ankle Surg 16:189-194

11. Henríquez H, Muñoz R, Carcuro G, Bastías C (2012) Is percutaneous repair better than open repair in acute Achilles tendon rupture? Clin Orthop Rel Res 470:998-1003. doi:10.1007/s11999-011-1830-1

12. Webb JM, Bannister GC (1999) Percutaneous repair of the ruptured tendo Achillis. J Bone Joint Surg Br 81:877-880

13. Ma GW, Griffith TG (1977) Percutaneous repair of acute closed ruptured achilles tendon: a new technique. Clin Orthop Relat Res 28:247-255

14. Schneppendahl J, Thelen S, Schek A, Bala I, Hakimi M, Grassmann JP, Eichler C, Windolf J, Wild M (2012) Initial stability of two different adhesives compared to suture repair for acute Achilles tendon rupture-a biomechanical evaluation. Int Orthop 36:627-632. doi:10.1007/s00264-011-1375-9

15. Amlang MH, Christiani P, Heinz P, Zwipp H (2005) Percutaneous technique for Achilles tendon repair with the Dresden instruments. Unfallchirurg 108:529-536

16. Assal M, Jung M, Stern R, Rippstein P, Delmi M, Hoffmeyer P (2002) Limited open repair of Achilles tendon ruptures: a technique with a new instrument and findings of a prospective multicenter study. J Bone Joint Surg Am 84:161-170

17. Guillo S, Del Buono A, Dias M, Denaro V, Maffulli N (2012) Percutaneous repair of acute ruptures of the tendo Achillis. Surgeon. doi:10.1016/j.surge.2011.12.002

18. Gigante A, Moschini A, Verdenelli A, Del Torto M, Ulisse S, de Palma L (2008) Open versus percutaneous repair in the treatment of acute Achilles tendon rupture: a randomized prospective study. Knee Surg Sports Traumatol Arthrosc 16:204-209

19. Maes R, Copin G, Averous C (2009) Is percutaneous repair of the Achilles tendon a safe technique? A study of 124 cases. Acta Orthop Belg 72:179-183

20. Huffard B, O'Loughlin PF, Wright T, Deland J, Kennedy JG (2008) Achilles tendon repair: Achillon system vs. Krackow suture: an anatomic in vitro biomechanical study. Clin Biomech 23:1158-1164 
21. Longo UG, Forriol F, Campi S, Maffulli N, Denaro V (2012) A biomechanical comparison of the primary stability of two minimally invasive techniques for repair of ruptured Achilles tendon. Knee Surg Sports Traumatol Arthrosc 20:1392-1397

22. Carmont MR, Highland AM, Rochester JR, Paling EM, Davies MB (2011) An anatomical and radiological study of the fascia cruris and paratenon of the Achilles tendon. Foot Ankle Surg $17: 186-192$

23. Feldbrin Z, Hendel D, Lipkin A, Zin D, Schorr L (2010) Achilles tendon rupture and our experience with the Achillon device. Isr Med Assoc J 12:609-612

24. Olsson N, Karlsson J, Eriksson BI, Brorsson A, Lundberg M, Silbernagel KG (2012) Ability to perform a single heel-rise is significantly related to patient-reported outcome after Achilles tendon rupture. Scand J Med Sci Sports. doi:10.1111/j.16000838.2012.01497.x

25. Lunsford BR, Perry J (1995) The standing heel-rise test for ankle plantar flexion: criterion for normal. Phys Ther 75:694-698

26. Talbot JC, Williams GT, Bismil Q, Shaw DL, Schilders E (2012) Results of accelerated postoperative rehabilitation using novel "suture frame" repair of Achilles tendon rupture. J Foot Ankle Surg $51: 147-151$

27. Maffulli N, Tallon C, Wong J, Lim KP, Bleakney R (2003) Early weightbearing and ankle mobilization after open repair of acute midsubstance tears of the achilles tendon. Am J Sports Med 31:692-700

28. Twaddle BC, Poon P (2007) Early motion for Achilles tendon ruptures: is surgery important? A randomized, prospective study. Am J Sports Med 35:2033-2038 